\title{
Estimativa da acidez potencial pelo método do pH SMP em solos da Microrregião Homogênea Brejo Paraibano
}

\author{
Lucia H. G. Chaves ${ }^{1}$, lêde B. Chaves ${ }^{2} \&$ Ana C. F. Vasconcelos ${ }^{3}$
}

\begin{abstract}
RESUMO
A utilização do pH SMP na estimativa da acidez potencial apresenta vantagens em relação ao método do acetato de cálcio $0,5 \mathrm{~mol} \mathrm{~L}^{-1}, \mathrm{pH} 7$, mas requer regionalização edafológica prévia para se estimar, com segurança, os valores de acidez potencial. Neste estudo se objetivou avaliar a relação solo-água-tampão que mais se adapte aos solos da Microrregião Homogênea Brejo Paraibano e ajustar uma equação de regressão que estime a acidez potencial desses solos por meio da obtenção do pH de equilíbrio da suspensão com a solução SMP. Cento e vinte amostras de solo daquela região, foram analisadas quanto à acidez potencial, pelo método usual; determinou-se, ainda, o pH SMP das suspensões solo-água-tampão 10:10:5, 10:20:10 e 10:25:5. Os resultados demonstraram que os teores de $\mathrm{H}+\mathrm{Al}$ se correlacionaram melhor com os valores de pH SMP obtidos com a suspensão 10:10:5 e que a equação $\ddot{y}=164,31-47,26 x+3,4717 x^{2}$, expressando os valores de $\mathrm{H}+\mathrm{Al}(\mathrm{ÿ})$ em $\mathrm{cmol}_{\mathrm{c}} \mathrm{dm}^{-3}$, pode ser utilizada para estimar teores de $\mathrm{H}+\mathrm{Al}$ dos solos estudados.
\end{abstract}

Palavras-chave: reação do solo, acidez de reserva, solução tampão

\section{Estimation of potential acidity by the pH SMP method in soils of the homogeneous micro-region of Brejo Paraibano}

\begin{abstract}
The use of the $\mathrm{pH}$ SMP to estimate the potential acidity has advantages in relation to the $0.5 \mathrm{~mol} \mathrm{~L}^{-1}, \mathrm{pH} 7$, calcium acetate method, but requires previous edaphic regionalization to estimate the potential acidity. The objectives of this study were to evaluate the soil-water-buffer ratio more adapted to soils from the homogeneous micro-region of Brejo Paraibano and to establish an equation to estimate the potential acidity of these soils by determination of the equilibrium $\mathrm{pH}$ of the soil suspension with the SMP solution. One hundred and twenty representative soils samples of the region were analyzed by the conventional calcium acetate method. Also determined was the $\mathrm{pH} \mathrm{SMP} \mathrm{in} \mathrm{the} \mathrm{equilibrium}$ suspensions soil-water-buffer 10:10:5, 10:20:10 and 10:25:5. The results have demonstrated that the best correlation between $\mathrm{H}+\mathrm{Al}$ values and $\mathrm{pH}$ SMP was obtained with the 10:10:5 suspension and that the equation $\ddot{y}=164.31-47.26 x+3.4717 x^{2}$, expressing $\mathrm{H}+\mathrm{Al}(\ddot{y})$ values in $\mathrm{cmol}_{\mathrm{c}} \mathrm{dm}^{-3}$, can be used to estimate $\mathrm{H}+\mathrm{Al}$ values of the studied soils.
\end{abstract}

Key words: soil reaction, potential acidity, buffer solution

1 UAEG/UFCG, CP 10087, CEP 58109-970, Campina Grande, PB. Fone: (83) 3310-1285. Email: Ihgarofalo@hotmail.com

2 DSER/UFPB, CEP 58930-000, Areia, PB. Fone: (83) 3362-2300. Email: iedebchaves@hotmail.com

${ }^{3}$ Engenheira Agrícola. Rua João Alves de Oliveira 70, CEP 58100-250, Campina Grande, PB. Fone: (83) 3321-1791. E-mail: ana3carol@yahoo.com.br 


\section{INTRODUÇÃO}

A acidez potencial, que é constituída pelos íons $\mathrm{H}^{+}$e $\mathrm{Al}^{3+}$ presentes nos colóides dos solos na maioria dos laboratórios brasileiros de análise de solo, é avaliada através da extração com soluções de sais tamponantes ou com misturas de sais neutros com soluções tampão (Peech, 1965). Um dos extratores mais utilizados nessa avaliação tem sido o acetato de cálcio $0,5 \mathrm{~mol} \mathrm{~L}^{-1}(\mathrm{pH} 7,0)$ que, apesar de considerado padrão (Raij et al., 1987), apresenta alguns inconvenientes, tais como os custos e o tempo operacional, pelo fato de envolver as etapas de extração e determinação titulométrica do $\mathrm{H}+\mathrm{Al}$ (Escosteguy \& Bissani, 1999); a dificuldade em se visualizar o ponto de viragem do indicador (Pereira et al., 1998) e a subestimação dos teores de $\mathrm{H}+\mathrm{Al}$ em solos com $\mathrm{pH}$ na faixa de 6,5 a 7,0 devido ao tamponamento deficiente dessa solução (Raij,1991); entretanto, a acidez potencial pode ser estimada pelo uso do pH SMP, o qual, segundo estudos desenvolvidos por Raij et al. (1987), Ciprandi (1993), Escosteguy \& Bissani (1999), Nascimento (2000), Silva et al. (2000), Gama et al. (2002), Sambatti et al. (2003) e Moreira et al. (2004), utilizando-se solos de várias regiões do País, é um método de fácil execução e apresenta boa correlação com a quantidade de $\mathrm{H}+\mathrm{Al}$ extraída com acetato de cálcio. Todos esses estudos enfatizam que a estimativa da acidez potencial pelo uso do $\mathrm{pH}$ SMP deve ser ajustada por região em virtude das variações encontradas entre as características físicas e mineralógicas dos diferentes tipos de solo.

Pelo método original proposto por Shoemaker et al. (1961) e McLean et al. (1960), o pH SMP corresponde ao valor de pH de equilíbrio de suspensões de solo-água-tampão na relação 5:5:10; no entanto, esta relação tem sido alterada de acordo com os tipos de solo estudados. Segundo Quaggio (1983), o método original SMP deve ser adaptado visando ao aumento da sua sensibilidade. Para alguns solos dos estados Rio Grande do Sul e Santa Catarina (Siqueira et al., 1987), é utilizada a relação solo-água-tampão de 6:6:6; já para outros tipos de solo do estado do Rio Grande do Sul, utiliza-se a relação 10:10:5 (Escosteguy \& Bissani, 1999); para os solos do estado de São Paulo, Raij et al. (1979) observaram que a relação 10:20:10 tornava o método muito sensível, enquanto Nascimento (2000) e Silva et al. (2000) empregaram, para os solos de vários estados da região semiárida brasileira, a relação 10:25:5, que também foi utilizada por Silva et al. (2002), Sambatti et al. (2003) e Moreira et al. (2004) para solos dos estados Paraná e Amazonas, respectivamente.

A Microrregião Homogênea Brejo Paraibano, com área de $2.239 \mathrm{~km}^{2}$ (SUDENE, 1972), ocupa 4\% da área total do estado. Apesar de pequena, é uma área agrícola importante para o estado da Paraíba devido às suas condições edafoclimáticas favoráveis à agricultura. Por outro lado, as precipitações pluviométricas predominantes na área (média de $1200 \mathrm{~mm}$ ) ao longo dos anos e seu uso contínuo com a agricultura, favoreceram a acidificação dos seus solos configurando, portanto, a necessidade da neutralização de sua acidez para um bom desenvolvimento agrícola.

Com base no exposto, o principal objetivo com este tra- balho foi avaliar a relação solo-água-tampão que mais se adeqüe aos solos da Microrregião Homogênea Brejo Paraibano e ajustar uma equação de regressão que tenha boa capacidade preditiva dos valores de $\mathrm{H}+\mathrm{Al}$ a partir do $\mathrm{pH}$ SMP, nos referidos solos.

\section{MATERIAL E MÉTODOS}

O trabalho foi realizado no Laboratório de Irrigação e Salinidade do Departamento de Engenharia Agrícola, que faz parte do Centro de Tecnologia e Recursos Naturais da Universidade Federal de Campina Grande. Utilizaram-se 120 amostras de solo $(0-0,20 \mathrm{~m})$ coletadas na Microrregião Homogênea Brejo Paraibano, estado da Paraíba, em locais de ocorrência de Argissolo Vermelho-Amarelo Distrófico, Neossolo Litólico Distrófico e Nitossolo Vermelho Eutrófico (EMBRAPA, 1999), os quais representam em torno de $70 \%$ da referida região.

Depois de secadas ao ar e passadas em peneira com malha de $2 \mathrm{~mm}$ de abertura, as amostras de solo foram submetidas a caracterização química, analisando-se o pH em água, pH SMP e acidez potencial $(\mathrm{H}+\mathrm{Al})$. $\mathrm{O}$ pH em água foi determinado na relação solo:água de 1:2,5 (EMBRAPA, 1997). A determinação de $\mathrm{H}+\mathrm{Al}$, em amostras de $5,0 \mathrm{dm}^{3}$ de terra fina secada ao ar, foi efetuada pela extração com acetato de cálcio $0,5 \mathrm{~mol} \mathrm{~L}^{-1}$ tamponado a $\mathrm{pH}$ 7,0 sendo os extratos titulados com solução hidróxido de sódio a $0,025 \mathrm{~mol} \mathrm{~L}^{-1}$ (EMBRAPA, 1997). A solução tampão SMP foi preparada segundo Quaggio \& Raij (2001) contendo, por litro, 3,6 g de p-nitrofenol, 6,0 g de cromato de potássio, 106,2 g de cloreto de cálcio, $4,0 \mathrm{~g}$ de acetato de cálcio e $5 \mathrm{~mL}$ de trietanolamina, tendo sido seu $\mathrm{pH}$ ajustado para 7,5 com 0,1 mol L-1 de $\mathrm{NaOH}$.

O pH SMP das amostras de solo foi definido considerando-se três diferentes relações entre solo:água:solução tampão, ou seja, 10:10:5, 10:20:10 e 10:25:5; após a adição da água e da solução tampão aos frascos contendo as amostras de solo, os mesmos foram agitados durante quinze minutos e deixados em repouso por uma hora; decorrido este tempo, procedeu-se à leitura do pH de equilíbrio das suspensões de solo com a água e solução tampão; as análises de pH SMP e de $\mathrm{H}+\mathrm{Al}$ foram efetuadas em três repetições; os dados obtidos, concentração de $\mathrm{H}+\mathrm{Al}$ e pH SMP, foram submetidos a análise de regressão; a escolha da melhor relação solo:água:tampão a ser utilizada na determinação do pH SMP dos solos analisados, foi feita com base no valor e na significância, analisada pelo teste t (Ribeiro Júnior, 2001), do coeficiente de determinação ajustado das equações que descrevem a relação entre as variáveis $\mathrm{pH}$ SMP e $\mathrm{H}+\mathrm{Al}$; a partir dessas equações estimaram-se os valores de $\mathrm{H}+\mathrm{Al}$ os quais foram correlacionados com os valores medidos e as diferenças entre eles $(\mathrm{H}+\mathrm{Al}$ medido $-\mathrm{H}+\mathrm{Al}$ estimado) corresponderam aos valores dos erros; a variabilidade dos valores estimados de $\mathrm{H}+\mathrm{Al}$ foi avaliada pela análise exploratória dos dados calculando-se média, valores máximo e mínimo, desvio padrão e coeficiente de variação (CV) (Ribeiro Júnior, 2001); de acordo com os valores de $\mathrm{CV}$, esta variabilidade foi classificada baixa $(\mathrm{CV}<12 \%)$, 
média $(12<\mathrm{CV}<62 \%)$ e alta $(\mathrm{CV}>62 \%)$ (Warrick \& Nielsen, 1980); a hipótese de normalidade dos valores estimados de $\mathrm{H}+\mathrm{Al}$ foi testada pelo teste de Komolgorov-Smirnov (KS) a $5 \%$ de probabilidade (Costa Neto, 1997).

\section{RESULTADOS E DISCUSSÃO}

As amostras de solo utilizadas no estudo apresentaram variação de pH em água entre 4,2 e 5,4 e os valores de pH SMP variaram, em média, de 5,1 a 6,9, dependendo da relação solo:água:tampão utilizada nas suas determinações, indicando a variação na acidez potencial dos solos da Microrregião Homogênea Brejo Paraibano.

As concentrações de $\mathrm{H}+\mathrm{Al}$ extraído com solução de acetato de cálcio $0,5 \mathrm{~mol} \mathrm{~L}^{-1}$ e os valores de $\mathrm{pH}$ SMP determinados nas suspensões correspondentes às relações solo: água:tampão 10:10:5, 10:20:10 e 10:25:5, se relacionaram inversamente (Figura 1); essas relações, por sua vez, são descritas satisfatoriamente pelas equações quadráticas (Figura 1) apresentando coeficiente de determinação $\left(R^{2}\right)$ significativo a nível de $1 \%$ de probabilidade. O modelo quadrático corrobora os obtidos no Nordeste Paraense (Gama et al.,
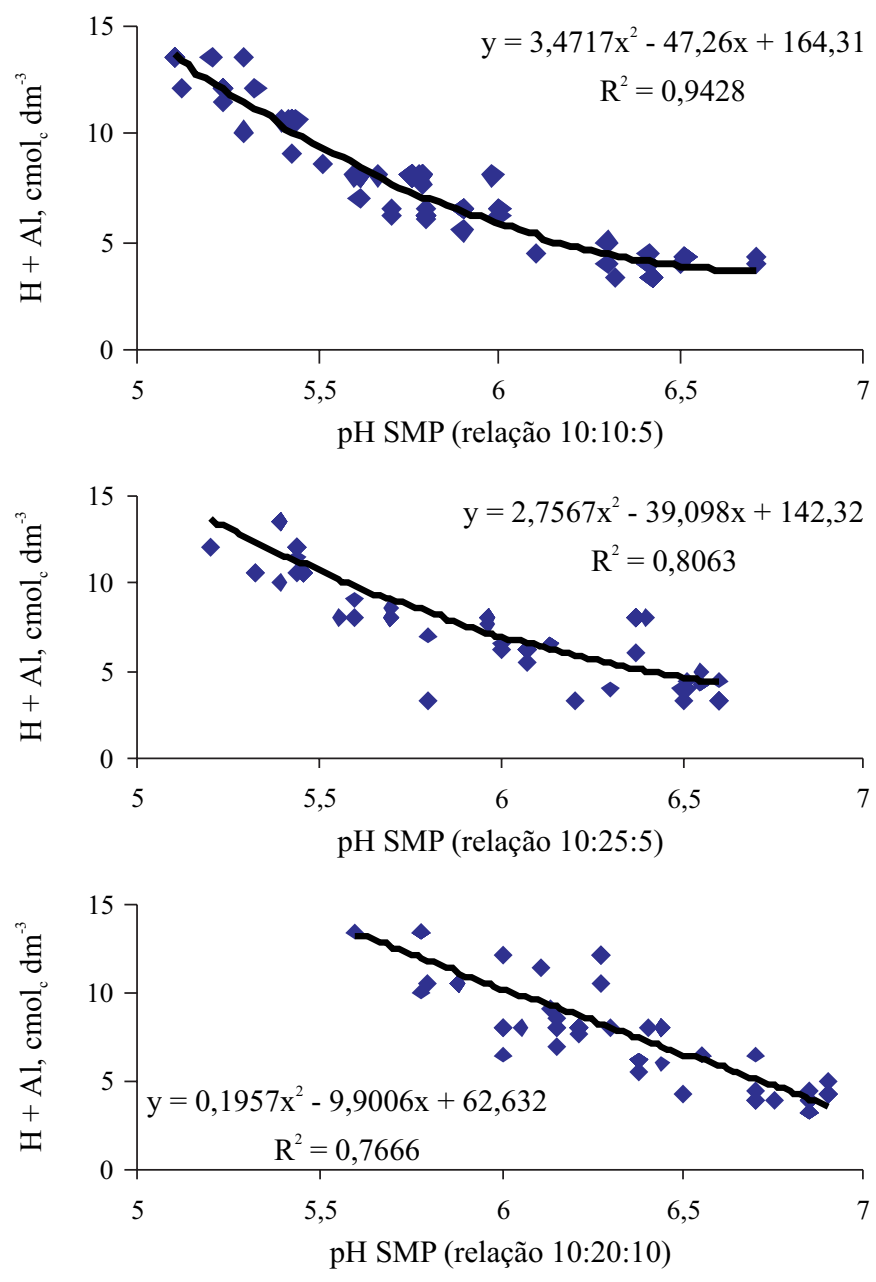

Figura 1. Relações entre teores de $\mathrm{H}+\mathrm{Al}$ e valores de $\mathrm{pH}$ SMP determinados com as relações solo:água:tampão 10:10:5, 10:20:10 e 10:25:5
2002) e no Semi-árido do Nordeste (Silva et al., 2000); nas demais regiões brasileiras já pesquisadas, as equações que apresentaram as melhores estimativas da acidez potencial foram a equação linear (Pereira et al., 1998; Sambatti et al., 2003; Moreira et al., 2004), e as equações exponencial e logarítmica (Sousa, et al., 1989; Escosteguy \& Bissani, 1999; Kaminski et al., 2002; Silva et al., 2002; Silva et al., 2006). Segundo Escosteguy \& Bissani (1999), os diferentes modelos matemáticos para descrever a relação entre a acidez potencial e pH SMP, decorrem das diferentes condições edafoclimáticas, o que reforça a idéia da necessidade do ajuste de um modelo matemático para cada localidade.

Nota-se, com base nos valores dos coeficientes de determinação das equações, que o uso das três relações solo:água:tampão não afetou muito a qualidade das correlações tendo, porém, as duas primeiras equações (relações 10:10:5 e 10:25:5) apresentado melhores ajustes o que, provavelmente, pode ser explicado pelo fato de ter sido usada nesse caso, menor quantidade de reativo (solução tampão) em relação à quantidade de solo, aumentando, segundo a literatura, a sensibilidade do método, principalmente para solos de baixo poder tampão (Raij et al., 1979), como é o caso dos solos estudados. Passando para 10:20:10, a relação solo:água:tampão diminuiu a sensibilidade do método tornando difícil sua aplicabilidade para esses solos; mesmo assim, os valores estimados da acidez potencial pelas três equações são maiores que os valores de acidez potencial determinados por titulação do extrato da solução de acetato de cálcio; enquanto estes variaram de 3,2 a $13,4 \mathrm{cmol}_{\mathrm{C}} \mathrm{dm}^{-3}$, os valores estimados pelas equações oscilaram de 3,51 a 13,58 $\mathrm{cmol}_{\mathrm{C}} \mathrm{dm}^{-3}$ (relação 10:10:5), de 3,63 a $13,32 \mathrm{cmol}_{\mathrm{c}} \mathrm{dm}^{-3}$ (relação 10:20:10) e de 4,35 a $13,55 \mathrm{cmol}_{\mathrm{c}} \mathrm{dm}^{-3}$ (relação 10:25:5) (Tabela 1). A estimativa desses valores pode tornar-se mais precisa na medida em que valores de acidez potencial e pH SMP de outras amostras de solo da Microrregião Homogênea Brejo Paraibano, forem sendo considerados na determinação das equações.

Com base no critério de Warrick \& Nielsen (1980), conclui-se a variabilidade dos valores estimados de $\mathrm{H}+\mathrm{Al}$, pelas equações correspondentes às três relações analisadas, pode ser classificada média $(12<\mathrm{CV}<62 \%)$ e, de acordo com o teste KS a 5\% de probabilidade, não houve distribuição normal para esses valores.

A Figura 2 mostra a relação entre os valores estimados de $\mathrm{H}+\mathrm{Al}$ pelas equações correspondentes às três relações

Tabela 1. Valores (mínimo, máximo e médio), desvio padrão e coeficiente de variação dos valores estimados de $\mathrm{H}+$ Al através das equações correspondentes às três relações solo:água:tampão utilizadas

\begin{tabular}{lccc}
\hline \multirow{2}{*}{ Medidas } & \multicolumn{3}{c}{ Valores estimados de H + Al } \\
\cline { 2 - 4 } & Relação 10:10:5 & Relação 10:20:10 & Relação 10:25:5 \\
\cline { 2 - 4 } Mínimo & 3,51 & 3,63 & 4,35 \\
Máximo & 13,58 & 13,32 & 13,55 \\
Média & 7,55 & 7,56 & 7,56 \\
Desvio-padrão & 3,01 & 2,71 & 2,78 \\
C.V.\% & 39 & 36 & 36 \\
\hline
\end{tabular}



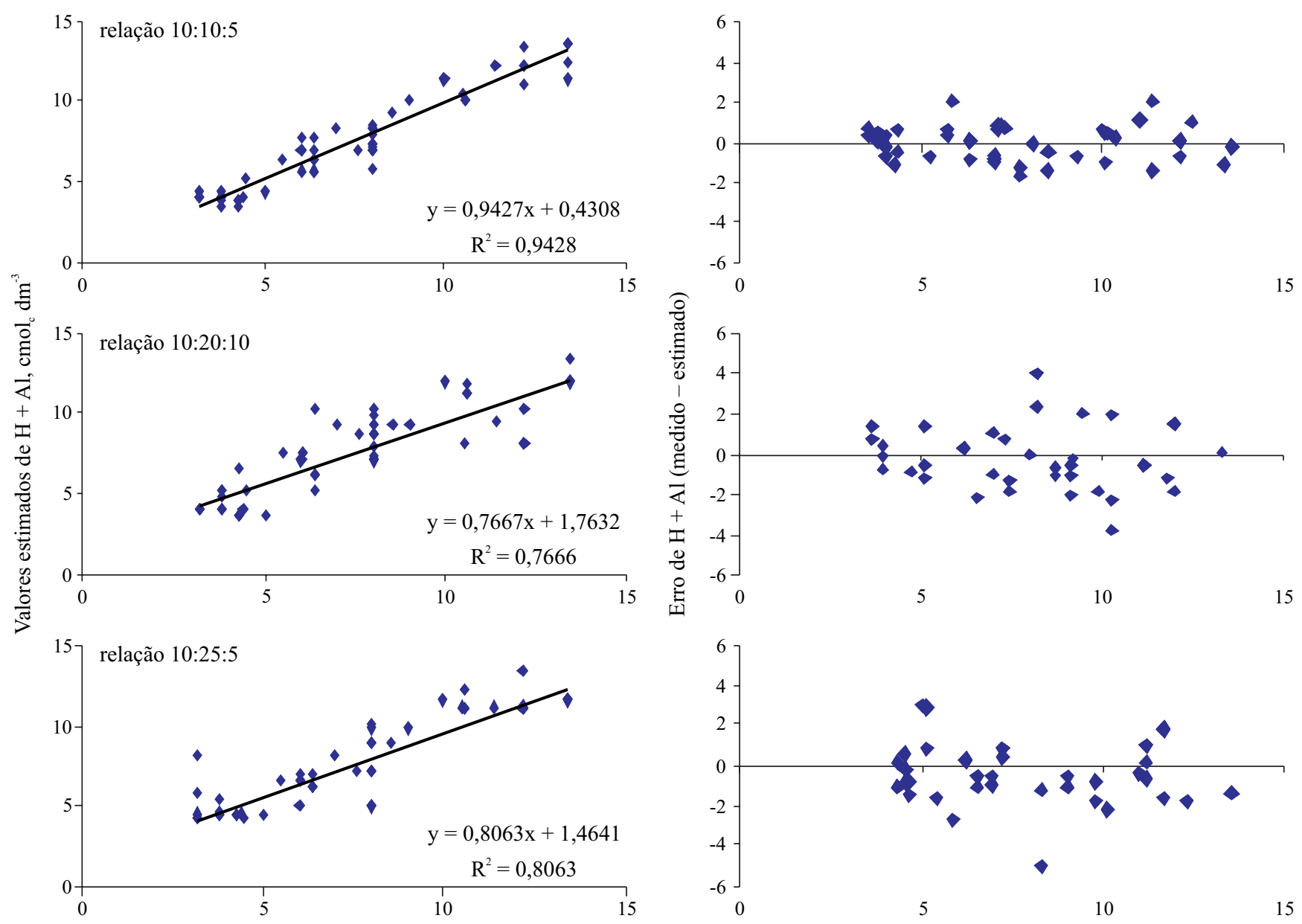

Valores medidos de $\mathrm{H}+\mathrm{Al}, \mathrm{cmol}_{\mathrm{c}} \mathrm{dm}^{-3}$

Figura 2. Relações entre os valores estimados pelo modelo quadrático correspondente à relação 10:10:5 e os medidos de $\mathrm{H}+\mathrm{Al}$

solo:água:tampão e os medidos de $\mathrm{H}+\mathrm{Al}$ por extração com acetato de cálcio $0,5 \mathrm{~mol} \mathrm{~L}^{-1}$, da mesma forma que a relação entre esses valores estimados e os erros $(\mathrm{H}+\mathrm{Al}$ medido $\mathrm{H}+\mathrm{Al}$ estimado). As relações entre os valores estimados e medidos de $\mathrm{H}+\mathrm{Al}$ são descritas satisfatoriamente pelas equações lineares apresentando coeficiente de determinação $\left(\mathrm{R}^{2}\right)$ significativo a nível de $1 \%$ de probabilidade; no caso da distribuição dos erros para as três relações estudadas se deu de forma aleatória o que, segundo Montgomery \& Peck (1992) demonstra que a distribuição dos dados foi adequada; comportamento semelhante foi observado por Sambatti et al. (2003) e Moreira et al. (2004) que trabalharam com solos do Estado do Paraná e do Estado do Amazonas, respectivamente, porém se observa que foi com a equação correspondente à relação 10:10:5 que ocorreram menos desvios da reta entre os valores estimados e os valores medidos, apresentando menor amplitude de erros que variaram de 2,15 a -1,64; as amplitudes dos erros das estimativas do $\mathrm{H}+\mathrm{Al}$, feitas pelas equações correspondentes às relações 10:20:10 e 10:25:5, foram maiores e variaram de 3,98 a -3,87 e de 2,99 a -5,08, respectivamente indicando que os valores obtidos de $\mathrm{H}+\mathrm{Al}$ através dessas equações, seriam ainda maiores que aqueles obtidos pela equação correspondente à relação 10:10:5, uma vez que a maior parte dos seus erros (57\%), se encontra dis- tribuída na parte negativa do eixo $\mathrm{Y}$ do gráfico cartesiano (Figura 2).

Considerando-se que a equação $\ddot{y}=164,31$ - 47,26x $+3,4717 x^{2}\left(R^{2}=0,94\right)$, obtida na relação $10: 10: 5$ foi a que melhor relacionou o pH SMP (x) com $\mathrm{H}+\mathrm{Al}(\ddot{\mathrm{y}})$, construiuse a Tabela 2 que permite estimar a acidez potencial $(\mathrm{H}+\mathrm{Al})$

Tabela 2. Conversão dos valores de pH SMP para $\mathrm{H}+$ Al para solos da Microrregião Homogênea Brejo Paraibano

\begin{tabular}{cccccc}
\hline $\mathbf{p H ~ S M P}$ & $\begin{array}{c}\mathbf{H}+\mathbf{A l} \\
\mathbf{c m o l}_{\mathbf{c}} \mathbf{d m}^{-3}\end{array}$ & $\mathbf{p H ~ S M P}$ & $\begin{array}{c}\mathbf{H}+\mathbf{A l} \\
\mathbf{c m o l}_{\mathbf{c}} \mathbf{d m}^{-3}\end{array}$ & $\mathbf{p H ~ S M P}$ & $\begin{array}{c}\mathbf{H}+\mathbf{A l} \\
\mathbf{c m o l}_{\mathbf{~ d m}} \mathbf{d m}^{-3}\end{array}$ \\
\hline 5,05 & 14,18 & 5,70 & 7,72 & 6,35 & 4,20 \\
\hline 5,10 & 13,58 & 5,75 & 7,35 & 6,40 & 4,05 \\
\hline 5,15 & 13,00 & 5,80 & 6,99 & 6,45 & 3,91 \\
\hline 5,20 & 12,43 & 5,85 & 6,65 & 6,50 & 3,80 \\
\hline 5,25 & 11,88 & 5,90 & 6,32 & 6,55 & 3,70 \\
\hline 5,30 & 11,35 & 5,95 & 6,02 & 6,60 & 3,62 \\
\hline 5,35 & 10,84 & 6,00 & 5,73 & 6,65 & 3,56 \\
\hline 5,40 & 10,34 & 6,05 & 5,46 & 6,70 & 3,51 \\
\hline 5,45 & 9,86 & 6,10 & 5,21 & 6,75 & 3,48 \\
\hline 5,50 & 9,40 & 6,15 & 4,97 & 6,80 & 3,47 \\
\hline 5,55 & 8,95 & 6,20 & 4,75 & 6,85 & 3,48 \\
\hline 5,60 & 8,53 & 6,25 & 4,55 & 6,90 & 3,50 \\
\hline 5,65 & 8,12 & 6,30 & 4,36 & 6,95 & 3,54 \\
\hline
\end{tabular}


Tabela 3. Estimativa dos teores de $\mathrm{H}+\mathrm{Al}$ no solo para valores de pH SMP na faixa de 4,5 a 6,0 por meio de equações ajustadas para diferentes estados e regiões brasileiras

\begin{tabular}{|c|c|c|c|c|c|}
\hline \multirow{3}{*}{ Estado ou Região } & \multirow{3}{*}{ Referência } & \multicolumn{4}{|c|}{ pH SMP } \\
\hline & & 4,5 & 5,0 & 5,7 & 6,0 \\
\hline & & \multicolumn{4}{|c|}{$\mathrm{H}+\mathrm{Al}\left(\mathrm{cmol}_{\mathrm{c}} \mathrm{dm}^{-3}\right)$} \\
\hline Minas Gerais & Correa et al. (1985) & 21,34 & 12,24 & 5,62 & 4,03 \\
\hline São Paulo & Quaggio et al. (1985) & 20,52 & 12,12 & 5,80 & 4,23 \\
\hline Paraná & Pavan et al.(1996) & 15,18 & 10,46 & 6,22 & 4,97 \\
\hline Rio de Janeiro & Pereira et al. (1998) & 23,51 & 14,12 & 6,91 & 5,09 \\
\hline Rio Grande do Sul e Santa Catarina & Escosteguy \& Bissani (1999) & 13,86 & 8,83 & 4,70 & 3,59 \\
\hline Pernambuco & Nascimento (2000) & 10,06 & 8,11 & 5,80 & 4,95 \\
\hline Nordeste & Silva et al. (2000) & 23,15 & 15,53 & 7,52 & 5,04 \\
\hline Nordeste Paraense & Gama et al. (2002) & 14,77 & 11,00 & 6,84 & 5,45 \\
\hline Norte de Minas Gerais & Silva et al. (2002) & 17,29 & 10,49 & 5,21 & 3,86 \\
\hline Noroeste Paranaense & Sambatti et al. (2003) & 8,27 & 6,95 & 5,09 & 4,30 \\
\hline Amazonas & Moreira et al. (2004) & 13,33 & 11,41 & 8,71 & 7,56 \\
\hline Vale do Jequitinhonha & Silva et al. (2006) & - & 13,99 & 6,37 & 4,55 \\
\hline Brejo Paraibano & Presente trabalho & 21,94 & 14,80 & 7,72 & 5,73 \\
\hline
\end{tabular}

a partir dos valores de pH SMP para os solos da Microrregião Homogênea Brejo Paraibano.

Os teores de $\mathrm{H}+\mathrm{Al}$ estimados pela equação que apresentou melhor ajuste para os solos da Microrregião Homogênea Brejo Paraibano (Tabela 2), usando-se quatro valores fixos de $\mathrm{pH}$ SMP, variando de 4,5 a 6,0 , foram comparados com os teores de $\mathrm{H}+\mathrm{Al}$ estimados por equações obtidas por diferentes autores, que trabalharam com solos de outros estados e regiões brasileiras (Tabela 3). Observa-se que, no intervalo de pH SMP escolhido, os valores de acidez potencial estimados para os solos da referida microrregião apresentaram tendência semelhante à indicada pelos valores obtidos para os solos do Rio de Janeiro (Pereira et al., 1998) e da região Nordeste (Silva et al., 2000); as demais equações, quando comparadas com a que melhor se ajustou neste trabalho, subestimariam a acidez potencial dos solos da Microrregião Homogênea Brejo Paraibano; essa subestimativa indica tendência de maior acidez potencial dos solos utilizados neste trabalho em relação aos solos dos demais estados. Apesar dessas observações, os dados apresentados na Tabela 3 mostram que não há, para um mesmo valor de $\mathrm{pH}$ SMP, similaridade nos valores obtidos para os solos analisados de diversos estados e regiões; conforme Nascimento (2000), este fato pode ser explicado pela diversidade de características químicas e mineralógicas de solo, que influem no seu tamponamento, corroborando a necessidade de ajuste regional para a estimativa da acidez potencial, pelo método pH SMP.

\section{CONCLUSÕES}

1. A sensibilidade do método $\mathrm{pH}$ SMP foi maior quando o pH de equilíbrio foi determinado na relação solo:água:tampão SMP de 10:10:5.

2. Os teores de $\mathrm{H}+\mathrm{Al}\left(\mathrm{cmol}_{\mathrm{C}} \mathrm{dm}^{-3}\right)$ dos solos da Microrregião Homogênea Brejo Paraibano podem ser satisfatoriamente estimados por meio do $\mathrm{pH}$ da solução tampão SMP, utilizando-se a equação $\ddot{y}=164,31-47,26 x+3,4717 x^{2}$.

\section{LITERATURA CITADA}

Ciprandi, M. A. O. Avaliação da metodologia da acidez ativa e potencial em solos do Rio Grande do Sul. Porto Alegre: UFRGS, 1993. 90p. Dissertação Mestrado

Corrêa, J. B.; Costa, P. C.; Lopes, A. S.; Carvalho, J. G. Avaliação de $\mathrm{H}+\mathrm{Al}$ pelo método SMP. In: Congresso Brasileiro de Pesquisas Cafeeiras, 12, 1985, Caxambu. Anais... Rio de Janeiro: Instituto Brasileiro do Café, 1985. p.111-112.

Costa Neto, P. L. O. Estatística. 15.ed. São Paulo: Edgard Blucher, 1997. 468p.

EMBRAPA - Empresa Brasileira de Pesquisa Agropecuária. Centro Nacional de Pesquisa de Solos. Manual de métodos de análise de solo. 2.ed. Rio de Janeiro: Ministério da Agricultura e do Abastecimento, 1997. 212p.

EMBRAPA - Empresa Brasileira de Pesquisa Agropecuária. Centro Nacional de Pesquisa de Solos. Sistema brasileiro de classificação de solos. Rio de Janeiro: Embrapa Solos, 1999. 412p.

Escosteguy, P. A.; Bissani, C. A. Estimativa de $\mathrm{H}+\mathrm{Al}$ pelo $\mathrm{pH}$ SMP em solos do Rio Grande do Sul e de Santa Catarina. Revista Brasileira de Ciência do Solo, Viçosa, v.23, n.1, p.175179, 1999.

Gama, M. A. P.; Prochnow, L. I.; Gama, J. R. N. F. Estimativas da acidez potencial pelo método SMP em solos ocorrentes no nordeste paraense. Revista Brasileira de Ciência do Solo, Viçosa, v.26, n.4, p.1093-1097, 2002.

Kaminski, J.; Gatiboni, L. C.; Rheinheimer, D. S.; Martins, J. R.; Santos, E. J. S.; Titssot, C. A. Estimativa da acidez potencial em solos e sua implicação no cálculo da necessidade de calagem. Revista Brasileira de Ciência do Solo, Viçosa, v.26, n.4, p.1107-1113, 2002.

McLean, E. O.; Shoemaker, H. E.; Hourigan, W. R. Some effects of aluminium on lime requirement Tests of Soils. In: Transaction International Congress of Soil Science, 7, 1960. Madison... Anais. Madison: Soil Science Society of American, 1960. p.142-151.

Montgomery, D.; Peck, E. A. Introduction to linear regression analysis. New York: John Wiley, 1992. 527p. 
Moreira, A.; Almeida, M. P.; Costa, S. G.; Santos, L. S. Acidez potencial pelo método do pH SMP no Estado do Amazonas. Pesquisa Agropecuária Brasileira, Brasília, v.39, n.1, p.89-92, 2004.

Nascimento, C. W. A. Acidez potencial estimada pelo pH SMP em solos do Estado de Pernambuco. Revista Brasileira de Ciência do Solo, Viçosa, v.24, n.3, p.679-682, 2000.

Pavan, M. A.; Oliveira, E. L.; Miyazawa, M. Determinação indireta da acidez extraível do solo $(\mathrm{H}+\mathrm{Al})$ por potenciometria com a solução tampão SMP. Arquivos de Biologia e Tecnologia, Curitiba, v.39, p.307-312, 1996.

Peech, M. Exchange acidity. In: Black, C. A. (ed.) Methods of soil analysis. Madison: American Society of Agronomy, 1965. p.905-913.

Pereira, M. G.; Valladares, G. S.; Souza, J. M. P. F.; Pérez, D. V.; Dos Anjos, L. H. C. Estimativa da acidez potencial pelo método do pH SMP em solos do estado do Rio de Janeiro. Revista Brasileira de Ciência do Solo, Viçosa, v.22, p.159-162, 1998.

Quaggio, J. A. Métodos de laboratório para calagem em solo. In: Raij, B. van; Bataglia, O. C.; Silva, N. M. (ed.). Reunião Brasileira de Fertilidade do Solo. Campinas. Anais... Campinas: IAC, 1983. p.33-48.

Quaggio, J. A.; Raij, B. van. Determinação do pH em cloreto de cálcio e da acidez total. In: Raij, B. van; Andrade, J. C; Cantarella, H.; Quaggio, J. A. (ed.). Análise química para avaliação da fertilidade de solos tropicais. Campinas: IAC, 2001. p.181-188.

Quaggio, J. A.; Raij, B. van; Malavolta, E. Alternative use of the SMP-buffer solution to determine lime requirement of soils. Communications in Soil Science and Plant Analysis, Philadelphia, v.16, p.245-260, 1985.

Raij, B. van. Fertilidade do solo e adubação. Piracicaba: Ceres, Potafos, 1991. p.343.

Raij, B. van; Cantarella, H.; Zullo, M. A. T. O método tampão SMP para determinação da necessidade de calagem de solos do estado de São Paulo. Bragantia, Campinas, v.38, n.7, p.57-69, 1979

Raij, B. van; Quaggio, J. A.; Cantarella, H.; Fereira, M. E.; Lopes, A. S.; Bataglia, O. C. Análise química do solo para fins de fertilidade. Campinas: Fundação Cargil, 1987. 170p.
Ribeiro Júnior, J. I. Análise Estatística no SAEG. Viçosa: UFV, 2001, 301p.

Sambatti, J. A.; Souza Junior, I. G.; Costa, A. C. S.; Tormena, C. A. Estimativa da acidez potencial pelo método do pH SMP em solos em formação Caiuá - Noroeste do Estado do Paraná. Revista Brasileira de Ciência do Solo, Viçosa, v.27, n.2, p.257264, 2003.

Shoemaker, H. E.; Mclean, E. O.; Pratt, P. F. Buffer methods for determining lime requirement of soils with appreciable amounts of extractable aluminium. Soil Science Society of American Proceedings, Madison, v.25, p.274-277, 1961.

Silva, C. A.; Avellar, M. L.; Bernardi, A. C. C. Estimativa da acidez potencial pelo pH SMP em solos do Semi-árido do Nordeste Brasileiro. Revista Brasileira de Ciência do Solo, Viçosa, v.24, n.3, p.689-692, 2000.

Silva, E. B.; Costa, H. A. O.; Farnezi, M. M. M. Acidez potencial estimada pelo método do pH SMP em solos da região do Vale do Jequitinhonha no Estado de Minas Gerais. Revista Brasileira de Ciência do Solo, Viçosa, v.30, n.4, p.751-757, 2006.

Silva, E. B.; Dias, M. S. C.; Gonzaga, E. I. C.; Santos, N. M. Estimativa da acidez potencial pelo $\mathrm{pH}$ SMP em solos da região Norte do Estado de Minas Gerais. Revista Brasileira de Ciência do Solo, Viçosa, v.26, n.2, p.561-565, 2002.

Siqueira, O. J. F.; Sherer, E. E.; Tassinari, G.; Anghinoni, I.; Patella, J. F.; Tedesco, M. J.; Milan, P. A.; Ernani, P. R. Recomendações de adubação e calagem para os Estados do Rio Grande do Sul e de Santa Catarina. Passo Fundo: Embrapa CNPT, 1987.100p.

Sousa, D. M. G.; Miranda, L. N.; Lobato, E.; Castro, L. H. R. Métodos para determinar a necessidade de calagem em solos dos cerrados. Revista Brasileira de Ciência do Solo, Campinas, v.13, p.193-198, 1989.

SUDENE - Superintendência do Desenvolvimento do Nordeste. Levantamento exploratório - Reconhecimento de solos do Estado da Paraíba. Rio de Janeiro: Ministério do Interior, 1972. 670p. Boletim Técnico, 15.

Warrick, A. W.; Nielsen, D. R. Spatial variability of soil physical properties the soil. In: Hill, D. (ed.). Applications of soil physics. New York: Academic Press, 1980. p.319-344. 